\title{
ANTIOXIDANT, ANTIBACTERIAL AND ANTIBIOFILM POTENTIALS OF ANISE (Pimpinella anisum) SEEDS EXTRACTED ESSENTIAL OILS
}
SH. A. Al- wendawi
L. A. Gharb
Assist Prof.
Lecturer
R. S. Al ghrery
Biologist

Dept. of Biology, College of Science, University of Baghdad, Baghdad/ Iraq

Shadan59alwendawi@gmail.com

\section{ABSTRACT}

lamyagharb@yahoo.com

Anise (Pimpinella anisum) is an annual herbaceous flowering plant, its widely used as spices, flavoring agent and fragrance. Anise seeds and its essential oils (EOs) has been used widely in the recipes of folk medicine in the Arab region, including Iraq. Therefore, the goal of this work was to extract and define the chemical compositions of aniseeds EOs, and study its antioxidant, antibacterial, and antibiofilm potentials. Aniseed EOs were extracted by hydro-distillation technique using Clevenger apparatus. Twenty-five distinct compounds have been recognized by Gas chromatographic-Mass spectral (GCMas) analysis, the major constituents were anisole (87.99\%) followed by estragole $(3.01 \%)$, and all other components were presented in less than $2 \%$. The aniseed EOs showed potent antioxidant activity for scavenging of 2,2 diphenyl - 1-picrylhydrazyl (DPPH) in concentrations-dependent manner, the highest antioxidant $(84.9 \pm 0.267 \%)$ was recorded at $10000 \mathrm{ppm}$. Antibacterial activity regards to minimum inhibitory concentration (MIC) against burn wounds isolated Pseudomonas aeruginosa were of the rang 4000-7000ppm. Aniseed EOs revealed excellent antibiofilm activity against $P$. aeruginosa biofilms formation with reduction percentage ranged from $26-86.41 \%$ in co-treatment assay, while the inhibition potentials for pre-developed biofilm decreased significantly $(P<0.05)$ by $100 \%$ for the majority of $P$. aeruginosa candidate isolates.

Key words: Medical plants, plants aromatic compounds, burn wounds, Pseudomonas aeruginosa, antimicrobial agents and minimum inhibitory concentration (MIC).

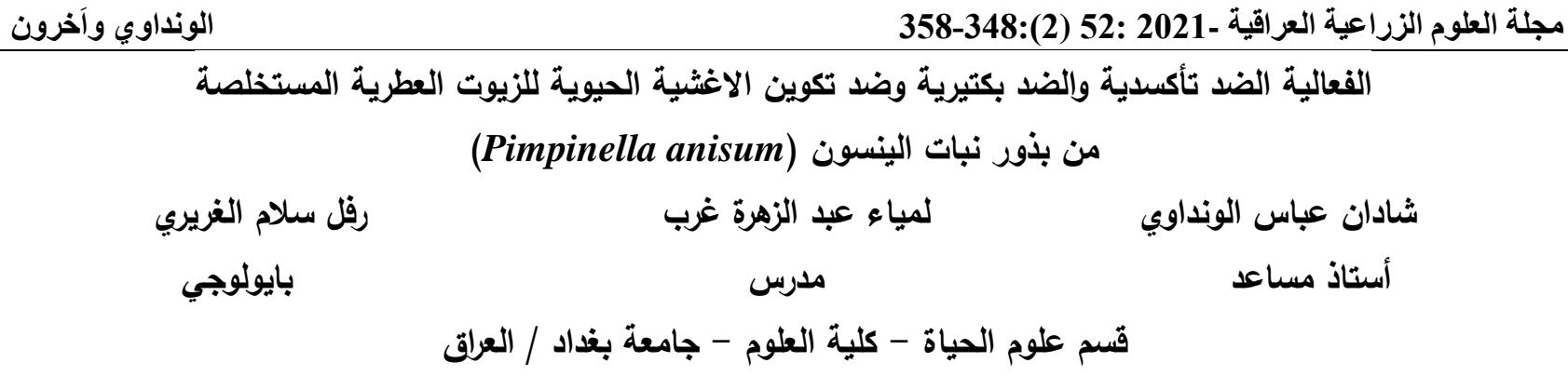




\section{INTRODUCTION}

Burns are considered to be devastating forms of trauma in patients with serious thermal injury. In most developing countries burning wound remains a major clinical challenge, and burning patients are very susceptible to infection due to the loss of skin barrier. The source of infection in most cases is the patient's normal flora or exogenous contamination, from contaminated wound dressing equipment's or from the hospital setting. Different groups of microorganisms have been reported to be associated with burns wound infections (27). Pseudomonas aeruginosa is Gram-negative opportunistic pathogen and its one of the most common bacteria in nosocomial infections (3). The bacterium is one of the leading microorganisms associated with burning wounds infections. P. aeruginosa is included in the category of community and hospital acquired pathogens in burn units, and therefore is considered as the most important factor in burning wound infections (18). The dramatical antimicrobial resistance of $P$. aeruginosa has led to serious restriction in the treatment of different pseudomonal infections. The speedy acquisition of multidrug resistance (MDR) in recent years has increased dramatically in $P$. aeruginosa (30). It became the main MDR bacteria, and has resulted in a strong demand for new therapy by consumers. $P$. aeruginosa is a pathogen presenting a large genome that can develop a large number of factors associated with MDR mechanisms, including, reduces the outer membrane permeability, expression of efflux pump, production antibiotic degrading enzymes, alginate production and transfer of resistance genes (3). Biofilm formation is one of the protecting strategies of $P$. aeruginosa makes the bacterium more difficult to treat than their planktonic counterparts, consequently leads to persistent, sometimes deadly, infections. Therefore, biofilm formation is one of the indirect modes of action by which bacteria are resistant to therapeutic agents. The physical barrier created by enclosed exopolymeric substances may account for enhanced antibiotic resistance in biofilms (16), a proportion of dormant bacteria that are inert toward antibiotics, and resistance genes that are unique to biofilms (25). Together, these bacterial characteristics that generate resistance to antibiotics, drive the need for a new approach that will kill bacterial biofilms efficiently. Globally plants are potential sources of novel antimicrobial compounds can be provided vast array of complex and structurally divers compounds. The aromatic volatile, essential oils (EOs) extracts from plants was approved to possess characteristics antimicrobial properties (28). The EOs are secondary metabolites that are synthesized in deferent parts of plants, they play a crucial ecological role in protecting producing plants against microorganisms, herbivores and other stresses, but also in attracting insect pollinators and seeds. EOs have a potential antiseptic, antibacterial, antiviral, antioxidant, antiparasitic, antifungal, and insecticide, and can therefore be a useful tool for reducing microbial resistance (23). The biological properties of EOs are generally characterized by their two or three major distinct components, which are present at relatively high concentrations (20-70\%) compared to other trace components (8). Plant EOs have been used for hundreds of years as natural medicines to combat a multitude of pathogens, including bacteria, fungi, and viruses. Several essential oils confer antimicrobial activity by damaging the cell wall and membrane, leading to cell lysis, leakage of cell contents, and inhibition of proton motive force (31). Among the plant's producers of aromatic compounds, is Anise (Pimpinella anisum), is herbal flowering plant which grow in several region all over the world, belonging to the Apiaceae family, one of the oldest medicinal plants in Iraq, the member of this family is well known for its distinctive flavors, which come from EOs and typical aromatic compounds. In fact, there is evidence that effectively kill microorganisms without promoting the development of resistance, with low toxicity to mammalian cells, and are relatively easy to obtain. They degrade quickly in water and soil, making them relatively environmentally friendly substances (5). The objective of this study was identification of hydro-distilled aniseed EOs and evaluate its antibacterial and antibiofilm potentials against MDR burns wound isolated $P$. aeruginosa, as well as 
investigation the antioxidative activity of the extracted EOs.

\section{MATERIALS AND METHODS}

Extraction of aniseed essential oil (EOs)

Anise (Pimpinella anisum) seeds used for extraction of aromatic EOs. Seeds were purchased from local market, and extraction was performed by using hydro-distillation method by Clevenger apparatus. $100 \mathrm{~g}$ of anise seeds was gently crushed and mixed with $600 \mathrm{ml}$ of distilled water. Then introduced to Clevenger apparatus which was previously prepared for distillation. The distillation carried out for $3 \mathrm{hr}$, the distillate was transferred to separate funnel, and allowed to settle down for $24 \mathrm{hr}$, until two phases of different density become visible, the upper layer representing EOs layer was withdrawn, and held in tightened vials at $4{ }^{\circ} \mathrm{C}$ for further laboratory analysis.

Gas chromatographic-mass spectral (GCMS) analysis of aniseed Eos

The aniseed EOs components were identified and quantified by means of GC-MS (Shimadzu GC-MS-QP2010 Plus). The carrier gas was helium at flow rate of $13 \mathrm{ml} \cdot \mathrm{min}^{-1}$, analyzer was used to identify the main chemical compounds in aniseeds oil. The mass spectrometer was set to scan $12.00-500.00 \mathrm{~m} / \mathrm{z}$. Samples were injected with a splitting ratio of 5.0 and the injector temperature was set to $280^{\circ} \mathrm{C}$. The total flow-rate was $13.1 \mathrm{ml}^{-\mathrm{min}^{-1}}$ and the column flow were $1.69 \mathrm{ml} . \mathrm{min}^{-1}$. The column oven temperature was $50^{\circ} \mathrm{C}$ and the hold time was $2-5 \mathrm{~min}$. The total run time was approximately $30 \mathrm{~min}$.

\section{Antioxidant potential of aniseed EOs}

The antioxidant activity of aniseed EOs was investigated in terms of free radical scavenging activity, using the radical solution, 2,2-Diphenyl-1-picrylhydrazyl (DPPH). The efficiency for scavenging DPPH was quantitatively evaluated by EOs ability to reduce and decolorize the purple-colored of DPPH solution to yellow (26). In brief, $100 \mu \mathrm{L}$ of different serial concentrations (1000 up to $10000 \mathrm{ppm}$ ) of aniseed EOs were mixed with equal volume of freshly prepared DPPH $(60 \mu \mathrm{M}$, in absolute methanol), the mixtures were vortexed and allowed to stand for $30 \mathrm{~min}$ in dark at $25^{\circ} \mathrm{C}$. The absorbance of resulting solution was measured at $517 \mathrm{~nm}\left(\mathrm{OD}_{517}\right)$ against blank (methanol). L-ascorbic acid $(0.1 \%)$ was used as reference antioxidant (positive control), and control was set up by mixing $100 \mu \mathrm{L}$ of distilled water with $100 \mu \mathrm{l}$ of DPPH. Assay were performed in triplicate. The percentage of scavenging activity against DPPH was calculated, based on control reading by following formula:

Reduction $\%=\left[\mathrm{A}_{0}-\mathrm{A}_{1} / \mathrm{A}_{0}\right] \times 100$

Where, $A_{0}$ is the absorbance of control, $A_{1}$ is the absorbance of sample.

\section{Antibacterial activity of aniseed EOs \\ Bacteria and growth conditions}

Forty identified $P$. aeruginosa isolates were used in the study, the bacterial isolates were obtained from sever burn wounds infection from patients attended to the burn's unit of $\mathrm{Al}$ wastey teaching Hospital / Baghdad. The identification of isolates was confirmed using Vitek 2 compact system. $P$. aeruginosa isolates were preserved on brain heart infusion agar (BHIA, Himedia/ India) at $4^{\circ} \mathrm{C}$, and refreshed every two weeks using same medium.

\section{In vitro antibacterial activity}

Antibacterial activity of aniseed EOs against $P$. aeruginosa planktonic forms was investigated by agar-well diffusion assay, using Mueller-Hinton agar (MHA, Himedia/India). The MHA plates were individually swab inoculated with $100 \mu \mathrm{L}$ of $P$. aeruginosa standardized inoculum $\left(10^{8}\right.$ $\mathrm{CFU} / \mathrm{ml}$, adjusted to MacFarland's standard No. 0.5). Wells of $5 \mathrm{~mm}$ size were made with sterile cork borer, $80 \mu \mathrm{L}$ of aniseed EOs added to wells, plates were incubated at $37^{\circ} \mathrm{C}$ for $24 \mathrm{hr}$. Antibacterial activity was evaluated by measuring the inhibition zone diameter (IZD), and sensitivity to EOs was classified to three categories. IZD $\leq 8 \mathrm{~mm}$ not sensitive, IZD $>$ 9-14 $\mathrm{mm}$ sensitive, and IZD $>15 \mathrm{~mm}$ highly sensitive (4).

\section{Minimal inhibitory concentration (MIC)}

The $P$. aeruginosa isolates that were exhibited high sensitivity to EOs action was included for MIC assay. The assay was carried out in triplicate by microdilution technique in 96well microtiter plates, $100 \mu \mathrm{l}$ of aniseed EOs was added to the first well of plate and serially diluted 1:1(1000 up to $10000 \mathrm{ppm}) .100 \mu \mathrm{L}$ of standardized bacterial inoculum $\left(10^{8} \mathrm{CFU} / \mathrm{ml}\right)$ were individually added to each well. The 
control was set up as $\mathrm{MH}$ broth and bacterial inoculum, plates incubated at $37^{\circ} \mathrm{C}$ for $24 \mathrm{hr}$. The MIC was determined visually as the lowest concentration that inhibited bacterial growth (14).

\section{Quantification on of biofilm formation}

The biofilm formation capacity of $P$. aeruginosa isolates was quantitatively assessed using microtiter plates. $P$. aeruginosa isolates were individually refreshed in BHI broth supplemented with $1 \%$ glucose. Aliquots $200 \mu \mathrm{l}\left(10^{8} \mathrm{CFU} / \mathrm{ml}\right)$ of each culture were dispensed to the wells, plates incubated at $37^{\circ} \mathrm{C}$ for $24 \mathrm{hr}$. Contents of wells were gently aspirated, wells washed 3-times with phosphate buffer saline (PBS), the attached bacteria were fixed using $2 \%$ sodium acetate, subsequently wells were stained with $0.1 \%$ crystal violet $(\mathrm{CV})$ solution for $15 \mathrm{~min}$, the excess stain was removed by washing with PBS three times, and $200 \mu 1$ of $95 \%$ ethanol was added to each well for $15 \mathrm{~min}$. Control was set up with $\mathrm{CV}$ binding to the wells exposed only to the culture medium without bacteria. Biofilm formation was measured at $620 \mathrm{~nm}\left(\mathrm{OD}_{620}\right)$ by ELISA microplate spectrometer (Asays, Belgium), assay was performed in triplicate and the mean biofilm absorbance was applied for calculation of biofilm generation degree as follow:

Biofilm = ODs-ODc

Where, ODs, donated the absorbance of samples, ODc, donated the absorbance of control.

According to the mean of $\mathrm{OD}$, the isolates were classified into three categories, based on the following criteria; ODs $\leq 2 \times$ ODc weak biofilm producer, ODs $\leq 4 \times$ ODc moderate biofilm producer, and $4 \times \mathrm{ODc}<\mathrm{OD}$ strong biofilm producer (8).

\section{Antibiofilm potentials of aniseed Eos}

Eight $P$. aeruginosa isolates that exhibited strong biofilm formation capacity were included to antibiofilm potentials assay. The assay was conducted in 96-well microtiter plates, and performed by two independent methods;

Inhibition of biofilm formation: it was evaluated by co-treatment assay (15). In each well of microtiter plate, $100 \mu \mathrm{L}$ of bacterial suspension $\left(10^{8} \mathrm{CFU} / \mathrm{ml}\right)$ was added, and 100 $\mu \mathrm{L}$ of aniseed EOs equivalent to $0.5 \times \mathrm{MIC}$,
$1 \times \mathrm{MIC}$ and $2 \times \mathrm{MIC}$ values were individually added to bacterial loaded wells. The microplates were incubated at $37^{\circ} \mathrm{C}$ for $24 \mathrm{hr}$. Well without addition of EOs was considered as a control, and blank well was set up as well with only EOs. Thereafter the biofilms formation ability was carried out by CV assay as previously described, and the assay was performed in triplicate. The biofilm inhibition efficacy of EOs, was expressed as percentage of biofilm reduction, based on control reading by the following formula:

Biofilm reduction $\%=[(\mathrm{C}-\mathrm{B})-(\mathrm{T}-\mathrm{B}) /(\mathrm{C}-$ B)] $\times 100$

Where; $\mathrm{B}$, denotes the average absorbance per well for blank (no biofilm, no treatment).C, denotes the average absorbance for control wells (biofilm, no treatment); $\mathrm{T}$, denotes the average absorbance per wells for treated wells (biofilm and treatment).

Inhibition of pre-developed biofilm. Biofilm formation was established as previously mentioned. After $6 \mathrm{hr}$ of incubation plates were removed from the incubator and $100 \mu \mathrm{l}$ of aniseed EOs at concentrations of $0.5 \times \mathrm{MIC}$, $1 \times \mathrm{MIC}$, and $2 \times$ MIC values were individually added to loaded wells, Plates were reincubated for $24 \mathrm{hr}$ at $37^{\circ} \mathrm{C}$. Well without addition of EOs was considered as control, and well with only EOs was set up as a blank well. Following incubation, plates were emptied and washed thrice with sterile PBS. the adherent cells were fixed with $2 \%$ sodium acetate, and biofilms detection was carried out by $\mathrm{CV}$ assay. Biofilm inhibition percentage was calculated using the same followed formula of co-treatment assay.

\section{Statistical analysis}

The Statistical Analysis System- SAS, program was used to detect the effect of difference factors in study parameters. Least significant difference -LSD test was used to significant compare between means in this study.

\section{RESULTS AND DISCUSSION}

The yield of aniseed (Pimpinella anisum) EOs after $3 \mathrm{hr}$ of hydro-distillation was $2 \%$. The oil was pale-yellow in color, with a mild aromatic odor. Several techniques had been involved for the extraction of EOs, like, hydro distillation, turbo distillation, super critical fluid extraction, solvent extraction, use of 
superheated and supercritical water and other such as microwave assisted processes, out of these techniques the hydro distillation is one of the ancient and official approved techniques for extraction of oil, and the superiority of aqueous extraction was indicated over other extraction techniques (11). Twenty-five distinct compounds have been recognized by GC-MS analysis, the main compounds are listed in table 1. and chromatogram is in fig.1, in order of their elution. The identification of GC peaks was made by compared their retention times (RT) with those of the original samples and by matching the MS data with those held in the Mass Spectra Library. The major constituents were anisole or transanethol $(87.99 \%)$ followed by estragole $(3.01 \%)$, and all other components were present in less than $2 \%$. It is clear that monoterpenes represent the main groups (90\%), and it is of interest to note the presence trans-anethol (bioactive compound), which is distinctive of anise and usually was detected in very high percentage (up to 93\%) in most of analyzed anise EOs. This finding is in accordance with previous articles related with anise derived EOs (22). The recorded percentage of estragole (the flavoring agent) was relatively high, as in most published experimental data is varied from 0.38 to $0.61 \%$. Moreover, high content $(1.54 \%)$ of the
Phyto marker phenylpropane [Phenol, 2methoxy-4-(1-propenyl)-, acetate] was detected. The increase in the accumulation of phenylpropane is consequence of environmental stress such as, pathogen attack, UV-irradiation, wounding, nutrient deficiency, and herbicide treatment (29), the ripening process was also demonstrated to affects the biosynthesis and the contents of Phyto markers (30). In general, the components of EOs vary between species, between portions of same plants, and among the geographical areas. The discrepancy in the composition of anise EOs grown in Iraq and elsewhere may be assigned to different factors, such as climate, season, high light impact, age of the plant, humidity of the harvested plant material, extraction technique and the existence of chemotypes (24). The composition and yield of EOs are impacted by numerous factors, in most cases it is difficult to isolate these factors from each other as they are interrelated and influence each other. These parameters include seasonal variations, the organ of the plant used, and the maturity of the plant, as well as its geographical origin and genetics. Generally, the biological properties of the EOs are determined by their major components including two groups of distinct biosynthetical origin (9)

Table 1. Main chemical compounds in anise seeds essential oils extracted by hydro-distillation

\begin{tabular}{|cccc|}
\hline Peak No. & Retention time & Composition $(\%)$ & Compound name \\
\hline 3 & 11.379 & 3.01 & estragole \\
5 & 13.854 & 87.99 & anisole \\
13 & 15.024 & 1.50 & 3,5,5-trimethyl-9-methylene 1H- Benzocycloheptene \\
17 & 15.647 & 1.54 & $3,5,5,9-$ tetramethyl 1H-Benzocycloheptene \\
23 & 19.505 & Phenol, 2-methoxy-4-(1-propenyl)-, acetate \\
\hline
\end{tabular}

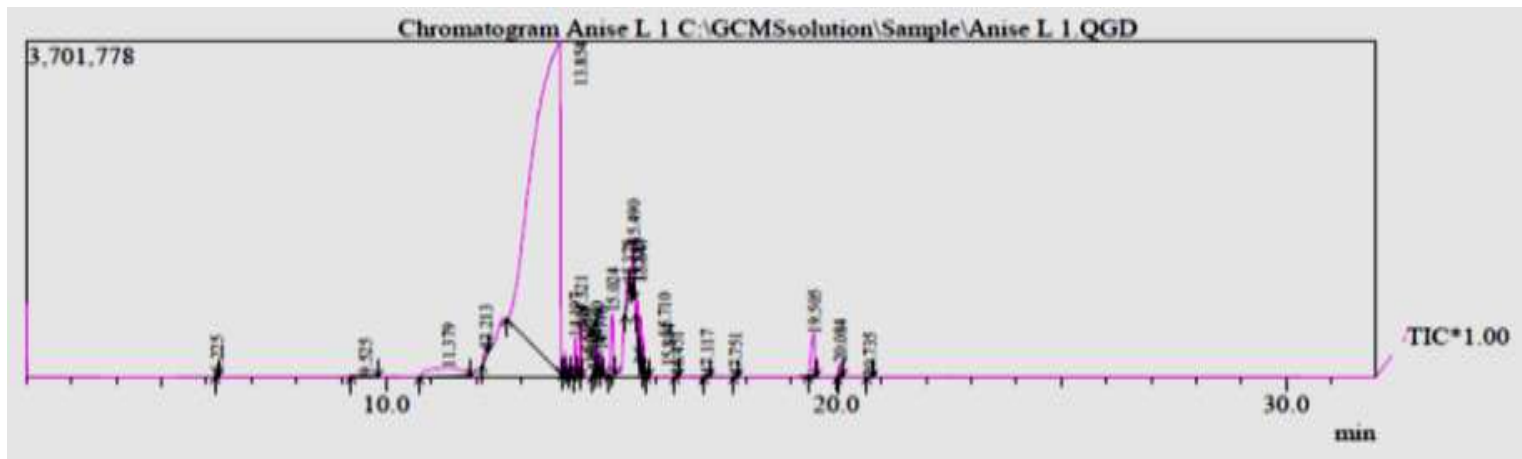

Figure 1. Gas chromatography spectra of aniseed essential oils extracted by hydro-distillation Anti-oxidant activity

The potential antioxidant activity of aniseed EOs was evaluated in respect of scavenging of DPPH solution. In concentration-dependent manner, EOs had potent antioxidant activity, the highest percentage scavenging of DPPH was $84.9 \%$, recorded for the highest used concentration (10000ppm), compared with 
ascorbic acid as a reference antioxidant (Fig.2).The experimental data in this work revealed that aniseed EOs exhibited reducing ability against the used free radicals, represented by discoloration of purple-colored DPPH, and this serves as a significant indicator of its potential antioxidant capacity (26)

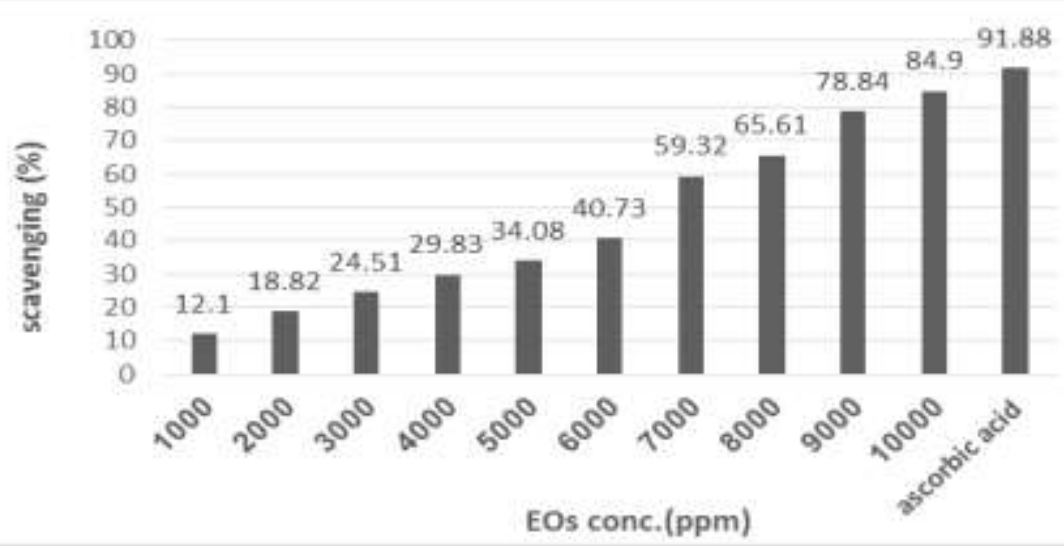

Figure 2. DPPH radical scavenging activity of aniseed EOs, each value represents means \pm $\mathrm{SD},(\mathbf{n}=3)$.

The aniseed EOs reducing capacity of DPPH have been confirmed in other studies. In both in vivo and in vitro experiments evidence have demonstrated significant antioxidant abilities of EOs from different plants against different free radicals' models (20). Antioxidant interact with free radicals and transfer either electrons or hydrogen atom, thus neutralized its free radical characteristic feature. Phenolic compounds are the main components that can donate hydrogen or electrons to free radicals and thus block the chain reaction of lipid peroxidation at the initiation stage. The high potency of phenolic compounds to scavenge radicals, owing to their phenolic hydroxyl groups (21). Indeed, redox properties of phenolic compounds allow them to fulfill multiple biological tasks, including, redox agents, hydrogen and electron donators, singlet oxygen quenchers as well as metal ions chelator (12). The major reason of antioxidant properties of aniseed EOs related to their high contents of total phenolic compounds. It has been reported that polyphenols contribute significantly to the total antioxidant potentials in fruits and vegetables. In current study, monoterpenes (phenolic compounds) were the major identified components of aniseed EOs, these have been considered as natural high antioxidants agents, which could be used as additives in food supplements to prevent the oxidative stress, which is the leading etiological cause of degenerative diseases in human. However, the effect of minor constituents of EOs should be considered as well, and the potential synergistic effects between these compounds might account for the antioxidant activity (9). In a study carried out in Iran, the antioxidative potentials of some umbelliferae belonged plants have been reported. Among the included plants, $P$. animus exhibited the strongest reducing activity against $\mathrm{DPPH}\left(\mathrm{IC}_{50}=109.80\right)$, and the study was confirmed positive correlation between antioxidant potency and phenolic contents of the studied fractions (6). The ethanolic extracted of aniseed EOs in concentration-dependent manner showed reducing scavenging activity against nitric oxide, superoxide and DPPH radicals. The alcoholic and water extract of aniseeds EOs displayed a marked antioxidative activity, in both linoleic acid and liposome model systems, and the water extract showed higher antioxidant activity than the corresponding alcohol fractions (9).

\section{Antimicrobial activity}

in vitro antibacterial activities of aniseed EOs against $P$. aeruginosa planktonic forms were assessed using agar-well diffusion method. EOs had certain antibacterial activity on majority of the experiment included pathogens. The candidate isolates exhibited different susceptibility profiles, high percentage of isolates were sensitive to introduced EOs. Hence, the susceptibility of bacteria was confined among three categories, 8 isolates were non-sensitive (20\%), 25 isolates were sensitive (62\%), while, 7 isolates exhibited high sensitivity (18\%). Meanwhile, 
the MIC values of aniseed EOs against selective isolates (highly sensitive $P$. aeruginosa isolates), were between 4000$7000 \mathrm{ppm}$. The isolate RS40 with a mean of MIC of $4000 \mathrm{ppm}$ was the most susceptible one to EOs action (Table.2 and Fig.3). P. aeruginosa is frequent cause of burns wound infections, and is one of the causes of delay in burn wounds healing (18). Recently $P$. aeruginosa was included to a comprehensive list of priority pathogens was released by the World Health Organization (WHO), these pathogens have high levels of resistance to most existing antibiotics such as carbapenem, vancomycin, penicillin, ampicillin, and the third-generation antibiotic cephalosporin (2). So, the toxicity of aniseed EOs against $P$. aeruginosa is of great relevance. On the other hand, $P$. aeruginosa is Gram-negative organism and Gram-negative bacteria generally had a higher resistance to the plant extracts and other antibacterial agents than Gram-positive bacteria. This attributed to the distinct feature of Gram-negative cell wall morphology, in contrast to those of Grampositive bacteria. Gram negative bacteria enclosed inside hydrophilic lipopolysaccharide outer layer, which is resistant to the penetration of antibacterial agents, as well as the presence of some lytic enzymes in the periplasmic space which attack and breaking down antibacterial molecules (4). Anise is one of many spices that contain bioactive constituents, phenolic and flavonoid compounds. The antibacterial activity of aniseed EOs can be assigned to their active components, such as anethole. Owing to existence of different bioactive components, there was not a specific mechanism for antibacterial effects of aniseed EOs, therefore referred to a cascade of damaging mechanisms, involving the entire bacterial cell. The proposed bactericidal mode of actions, including cell walls integrity disruption, loss of cell contents, destroying of cytoplasmic membrane and membranous proteins, coagulation of cytoplasmic fragile proteins, and dysfunction of the system activated proton transfer. Membrane damages are the most confirmed inhibitory effect of EOs (17). On the other hand, the MIC values of aniseed EOs was ranged from 4000 to 7000 ppm, that showing high values to resistant strains. These results agree with other studies that evaluated the MIC of EOs from different plants against $P$. aeruginosa (15).

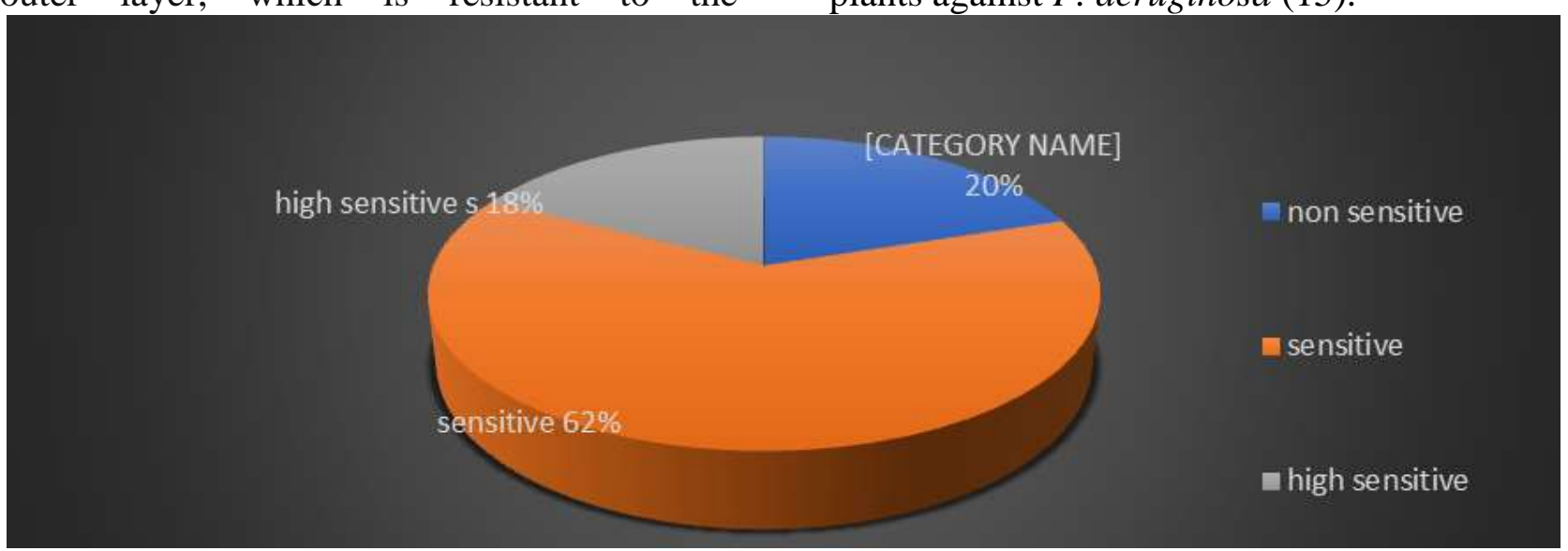

Figure 3. Susceptibility profile of burns wound isolated $P$. aeruginosa isolates to aniseed EOs Table 2. Antibacterial activity of aniseed EOs against $P$. aeruginosa isolates, in respect of presented inhibition zones (mm) and MIC values(ppm)

\begin{tabular}{|lcc|}
\hline $\begin{array}{c}\text { P. aeruginosa } \\
\text { isolates }\end{array}$ & $\begin{array}{c}\text { Antibacterial activity of aniseed EOs } \\
\text { Inhibition Zone }(\mathbf{m m})\end{array}$ & \\
\hline RS 4 & & $\mathbf{p p m})$ \\
RE10 & 12.6 & 6000 \\
RS 12 & 11.1 & 5000 \\
RS23 & 10.7 & 7000 \\
RS 28 & 10.2 & $\mathbf{7 0 0 0}$ \\
RS 37 & 9.5 & 6000 \\
RS40 & 9.6 & 4000 \\
\hline LSD value & 13.7 & $246.07 *$ \\
\hline & $2.884 *$ & \\
\hline
\end{tabular}




\section{Biofilm formation capacity}

The majority of burn wounds isolated $P$. aeruginosa were biofilm producers on polystyrene surface, in that 34 isolates $(85 \%)$ were able to form biofilm. Whereas, $8(23.5 \%)$ isolates were high biofilm producers with optical density $\left(\mathrm{OD}_{620}\right)$ values ranging from 0.95 to 0.467 , and $21(61.76 \%)$ isolates considered as moderate biofilm producers, while, $5(14.70 \%)$ isolates were weak biofilm producers. The other isolates $(15 \%)$ did not show any biofilm formation capacity (Fig.4). The $P$. aeruginosa tested isolates exhibited high productivity for biofilm generation compared to documented studies (19). $P$. aeruginosa is a gram-negative opportunistic pathogen known for its propensity to form biofilms (2). Biofilms are extracellular coating matrices, composed mainly of bacteria cells derived exopolysaccharides, extracellular DNA, proteins, and bacterial cells themselves. Several copies of the biofilm matrix, exopolysaccharides (alginate, Psl, and Pel) were recognized in the biofilms of $P$. aeruginosa (4). Majority of burns wound infection bacterial isolates are biofilm producers and are MDR strains.

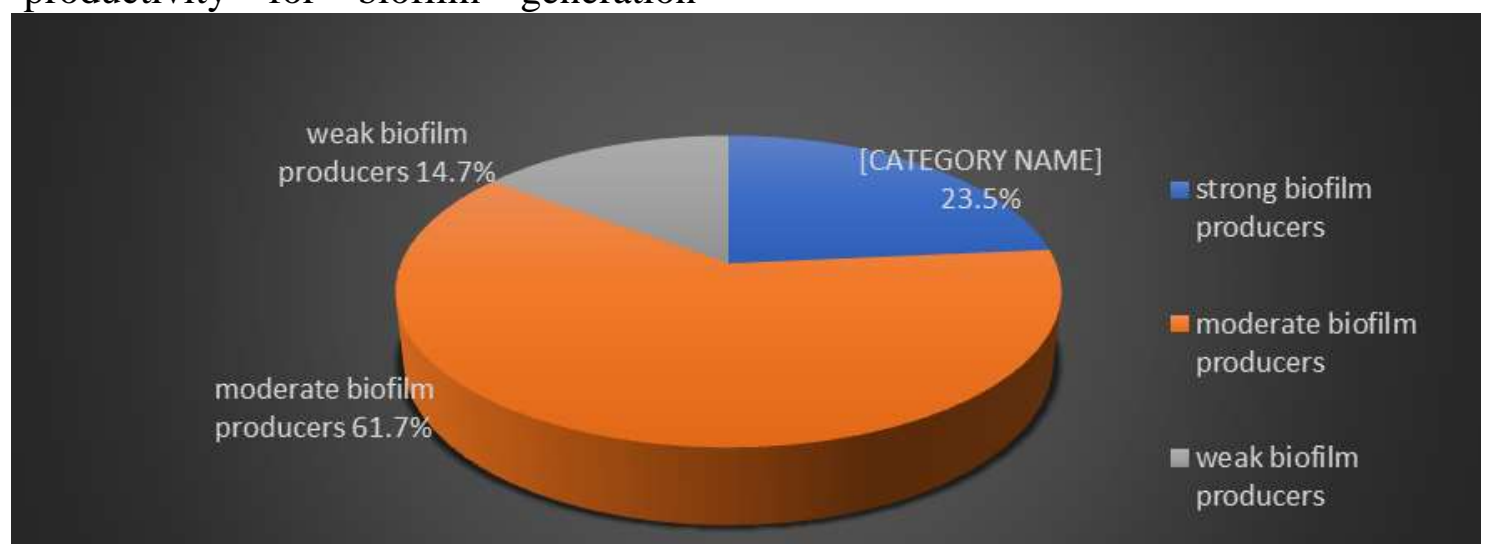

Figure 4. Biofilm formation capacity pattern of burns wounds isolated $P$. aeruginosa isolates Antibiofilm potentials detection

Inhibition of biofilm formation: Antibiofilm potentials of aniseed EOs was evaluated against selected high biofilm producer $P$. aeruginosa isolates ( 8 isolates), using various concentrations ranged from sub inhibitory concentration $(0.5 \times \mathrm{MIC})$ to double inhibitory concentration $(2 \times \mathrm{MIC})$, The $\mathrm{CV}$ assay showed that the biofilm formation was significantly inhibited $(\mathrm{p}<0.05)$ by all used MIC values. Whereas, in dose-dependent pattern the EOs consistently demonstrated inhibitory effect on biofilm mass, as the EOs concentrations increased the biofilm inhibition percentage also increased, with inhibition percentage ranged from 26 to $86.41 \%$. The maximum antibiofilm activity was recorded against the isolate $P$. aeruginosa $\mathrm{RS} 28$ at $2 \times \mathrm{MIC}$ concentration (Table .3).

Inhibition pre-developed biofilms: The aniseed EOs was extremely less potent against previously generated biofilm of $P$. aeruginosa, the inhibition rates decreased by $100 \%$ for the majority of tested isolates. However, less scoring was recorded at highest used concentration $(2 \times \mathrm{MIC})$ on the sensitive isolate

( $P$. aeruginosa $\mathrm{RS} 28$ ), the inhibition decreased by 3.4 folds, as $25.12 \%$ biofilm mass was reduced (Table .4). A key afforded feature by biofilm lifestyle is the inherent drug resistance brought to bacterial cells within the matrix. Bacterial cells residence within the biofilm architecture require nearly 1000x the antimicrobial concentration needed to kill their planktonic individuals (26). Therefore, finding out of alternative therapy for biofilm infections has become one of the attractive areas for researching in last few years. Plant derived EOs are well known for its antimicrobial activity against planktonic forms of bacteria (23). However, there is no enough information concerning the antibiofilm properties of plants EOs (1). Even though a few studies have shown that the bacterial biofilm could effectively inhibited by EOs such as cinnamon oil, eucalyptus and tea tree oil (10). Moreover, to best of our knowledge, this is the first study to provide data on aniseed EOs that play a role in the inhibition of biofilm generated by $P$. aeruginosa. In co-treatment assay the EOs achieved excellent biofilm removing potency, and this could be referring to interaction with 
bacterial surface proteins, that masking the phase of initial connection on surfaces. The success in inhibiting cellular link can be explained as the cellular connection, which is the initial stage in the formation of the biofilm. As well as the interfere of EOs with quorum sensing systems, considered one of worthy biofilms inhibition strategies, and this can be explained by the presence of phenolic compounds (monoterpenes), identified in this study, which are capable of reducing biofilm synthesis owing to their suppressive activity of the autoinducer-2 responsible for cell-to-cell communication in biofilm building steps (14). Unlike the excellent inhibitory activity against biofilms generation the EOs presented little or no inhibin activity on pre-developed biofilms.
This can be explained by the fact that the exopolysaccharide overproduction, which play a key role in protecting the metabolically active bacteria embedded in biofilm community, that the EOs could only attack the cells closest to biofilm interface (13).

\section{Conclusions}

Aniseed EOs could be considered a good source of compounds with significant antioxidant, antimicrobial, and antibiofilm potentials, which can be assigned to the high percentage of the main constituents (monoterpenes) or to synergistic effects among different constituents of EOs, which induced excellent biocidal effect against burns wounds opportunistic $P$. aeruginosa isolates.

Table 3. The antibiofilm potentials of aniseed EOs against $P$. aeruginosa biofilms, results are expressed as percentage of inhibition

\begin{tabular}{|c|c|c|c|c|}
\hline \multicolumn{5}{|c|}{ Biofilm Inhibition rate } \\
\hline Isolates & $0.5 \times$ MIC & $1 \times \mathrm{MIC}$ & $2 \times \mathrm{MIC}$ & LSD value \\
\hline RS5 & $30.3 \%$ & $74.0 \%$ & $56.0 \%$ & $7.82 *$ \\
\hline RS12 & $41.2 \%$ & $54.7 \%$ & $57.6 \%$ & $6.59 *$ \\
\hline RS22 & $45.6 \%$ & $48.0 \%$ & $73.3 \%$ & $4.97 *$ \\
\hline RS25 & $26.0 \%$ & $63.2 \%$ & $65.2 \%$ & $8.25 *$ \\
\hline RS28 & $61.02 \%$ & $68.1 \%$ & $86.41 \%$ & 8.97* \\
\hline RS31 & $50.8 \%$ & $85.7 \%$ & $83.11 \%$ & $7.55^{*}$ \\
\hline RS36 & $53.5 \%$ & $69.2 \%$ & $80.7 \%$ & $8.62 *$ \\
\hline RS40 & $42.8 \%$ & $77.12 \%$ & $86.41 \%$ & $8.96 *$ \\
\hline
\end{tabular}

Results are mean \pm SD, $(\mathrm{n}=3)$

Table 4. The antibiofilm potentials of aniseed EOs against $P$. aeruginosa generated biofilms. Results are expressed as percentage of inhibition

\begin{tabular}{|c|c|c|c|c|}
\hline \multicolumn{5}{|c|}{ Biofilm Inhibition rate } \\
\hline P. aeruginosa & $0.5 \times \mathrm{MIC}$ & $1 \times \mathrm{MIC}$ & $2 \times \mathrm{MIC}$ & LSD value \\
\hline RS5 & $0 \%$ & $0 \% \pm$ & $0 \%$ & $0.00 \mathrm{NS}$ \\
\hline RS12 & 0\% & $2 \% \pm$ & $14 \%$ & 2.71* \\
\hline RS22 & $\mathbf{0 \%}$ & $0 \% \pm$ & $\mathbf{0 \%}$ & $0.00 N S$ \\
\hline RS25 & $0 \%$ & $7.0 \% \pm$ & $0 \%$ & 2.18* \\
\hline RS28 & $0 \%$ & $0 \% \pm$ & $25.12 \%$ & $5.96 *$ \\
\hline RS31 & $0 \%$ & $0 \% \pm$ & $0 \%$ & $0.00 \mathrm{NS}$ \\
\hline RS36 & $0 \%$ & $0 \% \pm$ & $2.5 \%$ & $1.78^{*}$ \\
\hline RS40 & $0 \%$ & $\begin{array}{l}1.8 \% \pm \\
*(P \leq 0.05) .\end{array}$ & $4.26 \%$ & $1.96 *$ \\
\hline
\end{tabular}

Results are mean $\pm \mathrm{SD},(\mathrm{n}=3)$.

\section{REFERANCES}

1. AL-Gbouri, N.M. and A.M. Hamzah. 2018. Evaluation of Phyllanthus emblica extract as antibacterial and antibiofilm against biofilm formation bacteria. Iraqi J. of Agric. Sci. 49(1) :142-151.

2. Al-Ismail, K.M. and T. Aburjai. 2004. Antioxidant activity of water and alcohol extracts of chamomile flowers, anise seeds and dill seeds. J. of. Sci. Food and Agric., 84(2):173-178

3. Al Shaikh Faqri, A.M., N.H. Hyder. and A.H. Hashim. 2019. Induction of rhamnolipid production by Pseudomonas aeruginosa A3 using chemical and physical multigenic factor. Iraqi J. of Agric. Sci. 50(4):1174-1185

4. Biswas, B., K. Rogers., F. Mclaughlin., D. Daniels. and A. Yadav. 2013. Antimicrobial activities of leaf extracts of guava (Psidium 
Guajava L.) on two gram-negative and grampositive Bacteria. Int. J Microbiol. 2013: 21-28 5. Burt, S. 2004. Essential oils: their antibacterial properties and potential applications in foods--a review. Int. J. of Food Microbiol. 94(3):223-53

6.Dhifi, W., S. Bellili., S. Jazi., N. Bahloul. and W. Mnif. 2016. The essential Oils' Chemical Characterization and investigation Some biological Activities: A Critical Review. Medicines.3(4):25-41

7. Djihane, B., N. Wafa., S. Elkhamssa., A. Maria. and Z.M. Mihoub. 2017. Chemical constituents of Helichrysum Italicum (Roth) G. Don essential oil and their antimicrobial activity against gram-positive and gramnegative Bacteria, filamentous Fungi and Candida Albicans. Saudi. Pharm. J. 25(5):780787

8. Driscoll, J.A., S.L. Brody. and M.H. Kollef. Drugs. 2007. The epidemiology, pathogenesis and treatment of Pseudomonas aeruginosa infections. Drugs. 67(3):351-68

9. Ghasemzadeh, A., V. Omidvar. and H.Z. Jaafar. 2012. Polyphenolic content and their antioxidant activity in leaf extract of sweet potato (Ipomoea batatas). J. of Medicinal Plants Research. 6: 2971-2976.

10. Hammer, K., C. Carson. and R. Riley. 1999. Antimicrobial activity of essential oils and other plant extracts. J. Appl. Microbiol. 86:985-990

11. Heo, B.G., Y.J Park., Y.S. Park., J.H. Bae., J.Y. Cho., K. Park., Z. Jastrzebski. and S. Gorinstein. 2014. Anticancer and antioxidant effects of extracts from different parts of indigo plant. Ind Crop Prod. 56:9-16

12. Hossain, M.A., M.D. Shah., S.V. Sang. and M. Sakari. 2016. Chemical composition and antibacterial properties of the essential oils and crude extracts of Merremia borneensis. Science. J. of cognate chemst. 2(1):243-249

13. Karpanen, T.J., T. Worthington., E.R., Hendry., B.R. Conway. and P.A. Lambert 2008. Antimicrobial efficacy of chlorhexidine digluconate alone and in combination with eucalyptus oil, tea tree oil and thymol against planktonic and biofilm cultures of $S$. epidermidis. J. of antimicrob. Chemo. 62:1031-1036

14. Kifer, D., V. Muzingc. and M.S. Klaric. 2016. Antimicrobial potency of single and combined mupirocin and monoterpenes, thymol, menthol and 1,8-cineole against $S$. aureus planktonic and biofilm growth. The J. of Antibiotics (Tokyo), Zagreb. 69(9): 689696

15. Lakehal, S., A. Meliani., S. Benmimoune., S.N. Bensouna., F.Z. Benrebiha. and C. Chaouia. 2016. Essential oil composition and antimicrobial activity of Artemisia herbaalba Asso grown in Algeria. Med. Chem. 6:435-439.

16. Lynch, A.S. and G.T Robertson. 2008. Bacterial and fungal biofilm infections. Annu. Rev. Med. 59:415-28

17. Macwan, S.R., B.K. Dabhi., K.D. Aparnathi. and J.B. Prajapati.2016. Essential oils of herbs and spices: Their antimicrobial activity and application in preservation of food. Int. J. currn. Microbiol. Appl. Sci, 5:885-901

18. Martini, A., H. Marzouki., H. Hentati., M. Aouni. and M. Mastoiri. 2016. Antibacterial and antibiofilm activities of Laurusno bilis L. essential oils against Staphylococcus aureus strains associated with oral infections. Current Research in Translational Medicine. 64(1):.29-34

19. Nageires, M. O., Â. Pawlowski., C. A. Zini., G. L Soares., A. S. Motta and A.P.G. Frazzon.2016. Antimicrobial and antibiofilm activity of Baccharis psiadioides essential oil against the antibiotic resistant strains of Enterobacter faecalis. Pharmaceutical Biology. 54(12): 3272-3279

20. Naik, G.H., K.I. Priyadarshini., V.J. Sata., M.M. Banavalikar., D.P. Sohoni., M.K. Biyani. and H. Mohan. 2003. Comparative antioxidant activity of individual herbal components used in ayurvedic medicine. Phytochemistry. 63(1): 97-104

21. Oke, F., B. Aslim., S. Ozturk. and S. Altundag. 2009. Essential oil composition, antimicrobial and antioxidant activities of Satureja cuneifolia Ten. Food Chemistry. 112: 874-879.

22. Patel, P., S. Joshi, S. and R. Bharadwaj. 2015.Aerobic bacterial infections in a burn's unit of Sassoon General Hospital, Pune. International J. of Healthcare and Biomedical Research. 3(3):106-112

23. Raal, A. A. and E. Arak. 2008. Essential oil composition of Pimpinella animus L., fruits 
from various European countries. Natural Prod. Res, 22: 227-232

24. Rajeshwari, C.U., M. Abirami. and B. Andallu. 2011. In vitro and in vivo antioxidant potential of aniseeds (Pimpinella animus). Asian J. of Experimental Biol science. 2(1):8089

25. Saffari, M., S. Karami. and F. Firoozeh. 2017. Evaluation of biofilm-specific antimicrobial resistance genes in Pseudomonas aeruginosa isolates in Farabi Hospital. Medical Microbiol. J. 66(7):905-909

26. Sanchez-Moreno, C. 2002. Methods used to evaluate the free radical scavenging activity in foods and biological systems. Food Sci Tech Int. 8:121-137
27. Santucci, S.G., S. Gobara., S. Santos., C.R. Fontana. and A.S. Levin. 2003. Infections in a burn intensive care unit: experience of seven years. J Hosp Infect, 56:6-13

28. Sindhu, M.T., A. Emilia. and A.Z. Zakaria. 2015. Reactivity of phenolic compounds towards free radicals under in vitro conditions, J. of food. Sci.and Technol.52(9):5790-5799 29. Taiz, T. and E. Zeiger. 2002. Plant Physiology 3rd ed. Secondary metabolites and plant defense, 283-308.

30. Tawfiq, S.M. 2018 Bacteriological and genetic study of Pseudomonas aeruginosa isolates. Iraqi J. of Agric. Sci., ,44(1): 22-35. 31. Verma, N. and S. Shukla. 2015. Impact of various factors responsible for fluctuation in plant secondary metabolites. J. Appl. Res. Med. Arom. Plant,2 (4):105-113. 